\title{
Serum BTP concentrations are not affected by hepatic dysfunction
}

Debarati Chakraborty ${ }^{1 \dagger}$, Ayub Akbari ${ }^{2,3,4}$, Greg A. Knoll ${ }^{2,3,4}$, Jennifer A. Flemming ${ }^{5,6}$, Catherine Lowe ${ }^{5}$, Shareef Akbari $^{3}$ and Christine A. White ${ }^{1 * \dagger}$ (D)

\begin{abstract}
Background: Beta Trace Protein (BTP) is a promising marker of glomerular filtration rate (GFR). Equations to estimate GFR using BTP have been proposed. Very little is known about BTP's production and metabolism. It has been hypothesized that the liver metabolizes certain BTP isoforms. As such, hepatic dysfunction may influence serum levels independently of GFR. This would impact on the accuracy and precision of GFR estimates using BTP. The purpose of this study was to assess the impact of cirrhosis on serum BTP concentrations.

Methods: BTP, cystatin C (cysC) and creatinine ( $\mathrm{Cr}$ ) were measured in 99 cirrhotic subjects and in matched controls. BTP/cysC and $\mathrm{Cr} / \mathrm{cys} \mathrm{C}$ ratios were compared between cases and controls. This was repeated after stratification by Child Pugh category. Comparisons of ratios between Child Pugh category A and combined B and C case subjects were also performed.

Results: There were no differences in BTP/CysC ratios between cases and controls for the entire cohort (0.80 vs 0.79 ) or for any of the Child Pugh categories ( $p>0.10)$. There were significant differences between cases (1.09) and controls (0.73) for the BTP/Cr ratios $(p<0.001)$. The BTP/Cr ratio was higher in those with more advanced cirrhosis as compared to those with less severe cirrhosis (1.20 vs 1.03, $p<0.01)$. There were no differences in BTP/cysC ratios between those with less severe and more advanced cirrhosis $(p=0.25)$.

Conclusions: This study suggests that hepatic dysfunction does not influence serum BTP levels and argues against a significant role for the liver in BTP metabolism. Confirmation in a larger group of patients with advanced cirrhosis is required.
\end{abstract}

Keywords: Beta trace protein, Cirrhosis, Creatinine, Cystatin C, Glomerular filtration rate

\section{Background}

Beta Trace Protein (BTP) is a low molecular weight glycoprotein and a novel endogenous marker of glomerular filtration rate (GFR) [1]. First described in 1961 [2], it was noted to be increased in the serum of patients with renal disease in 1997 [3]. Subsequent investigations have examined the utility of BTP as a marker of GFR in a variety of patient populations [4-9]. Some evidence suggests that it is more sensitive than creatinine $(\mathrm{Cr})$ at detecting early changes in GFR [10, 11]. Several BTPbased GFR estimation equations have been proposed [8, $12-15]$. These however have generally been found to less

\footnotetext{
* Correspondence: cw38@queensu.ca

${ }^{\dagger}$ Equal contributors

${ }^{1}$ Division of Nephrology, Department of Medicine, Queen's University,

Etherington Hall, 94 Stuart Street, Kingston, ON K7L 2N6, Canada

Full list of author information is available at the end of the article
}

accurate and more imprecise than equations containing $\mathrm{Cr}$ and cystatin $\mathrm{C}$ (cysC) suggesting a greater impact of non-GFR determinants on serum BTP concentrations as compared to the other two filtration markers $[8,16]$. NonGFR determinants of BTP concentrations thus further identified include serum albumin concentration, gender, urine protein excretion and weight $[17,18]$.

Unlike $\mathrm{Cr}$, very little is known about the origin and metabolism of BTP. BTP is a heterogeneous glycoprotein with multiple isoforms and is present in various fluid compartments including blood, urine and cerebral spinal fluid (CSF) [1, 3]. Smaller non-sialyzed isoforms predominate in the CSF whereas the larger sialylated isoforms predominate in the serum and urine [3]. While a number of cell types have been demonstrated to produce BTP, the origin of serum BTP is unclear [1]. It 
has been hypothesized to result from diffusion from the CSF based on the glycosylation patterns of BTP glycoforms which are most typical for CSF as supposed to hepatic glycoproteins $[2,3]$. In an animal study, intrathecally administered recombinant BTP was recovered from serum lending support for a CNS origin [19]. It has been further hypothesized that the non-sialylated "brain" glycoforms are then rapidly eliminated from blood by the liver leaving a predominance of the "blood/ urine" sialylated glycoforms [3].

The impact of hepatic dysfunction on serum BTP concentrations has never been investigated. Its effect on serum $\mathrm{Cr}$ concentrations is well recognized with depressed serum concentrations due to decreased hepatic synthesis of its precursor creatine, malnutrition and muscle wasting [20, 21]. These factors significantly hamper the assessment of kidney function in cirrhotics [20-22]. If the above described hypotheses are correct, non-sialyated BTP isoforms would accumulate in the circulation in the setting of hepatic dysfunction, leading to increased serum levels and reduced accuracy of BTPbased GFR estimates. The aim of this study was to determine whether patients with hepatic dysfunction have higher than expected serum BTP concentrations due to reduced hepatic clearance of the non-sialyzed isoforms.

\section{Methods}

This case-control study received institutional ethics approval and was conducted between June-October 2014 at the academic hospitals of Queen's University Kingston, ON, Canada. Case subjects were recruited in the tertiary care Liver Clinic staffed by two subspecialty trained hepatologists and included if they had a diagnosis of cirrhosis and excluded if they were dialysis dependent or had known acute kidney injury. The diagnosis of cirrhosis was confirmed by the hepatologists according to standard clinical criteria of either 1) cirrhosis on liver biopsy; 2) evidence of portal hypertension or hepatic decompensation in the form of ascites, esophageal varices or hepatic encephalopathy or; 3) Non-invasive testing (FibroTest $\odot$ or FibroScan $\odot$ ) estimating F4 fibrosis in an individual with known chronic liver disease. Basic demographic, clinical and laboratory data were collected including diabetes status, etiology of cirrhosis, presence of ascites or encephalopathy, INR, albumin and bilirubin. Child Pugh Class and MELD scores were calculated [23, 24]. The Child Pugh classification incorporates five variables (albumin, ascites, encephalopathy, INR) while the MELD score includes bilirubin, $\mathrm{Cr}$, and INR (Table 1).

Control subjects consisted of patients attending renal clinics who had blood work done in clinic as part of routine clinical care. Exclusion criteria were known liver disease or cirrhosis. Renal patients were chosen as the control group because they have sufficient residual
Table 1 Child Pugh and MELD scores

\begin{tabular}{|c|c|c|c|}
\hline \multicolumn{4}{|l|}{ Child Pugh $^{\mathrm{a}}$} \\
\hline Measure & 1 point & 2 points & 3 points \\
\hline Bilirubin, (mg/dl) & $<2$ & $2-3$ & $>3$ \\
\hline Albumin, $\mathrm{g} / \mathrm{dl}$ & $>3.5$ & $2.8-3.5$ & $<2.8$ \\
\hline INR & $<1.7$ & $1.71-2.30$ & $>2.30$ \\
\hline Ascites & None & Mild & Moderate to severe \\
\hline Hepatic encephalopathy & None & $\begin{array}{l}\text { Grade I-II } \\
\text { (or suppressed) }\end{array}$ & $\begin{array}{l}\text { Grade III-IV } \\
\text { (or refractory) }\end{array}$ \\
\hline \multicolumn{4}{|l|}{ MELD score ${ }^{b}$} \\
\hline \multicolumn{4}{|c|}{$\left(0.957 * \log _{e}(\right.$ creatinine $)+0.378 * \log _{e}($ bilirubin $)+1.120 * \log _{e}($ INR $\left.)+0.6431\right) * 10$} \\
\hline
\end{tabular}

serum left after their routine biochemistry is performed to allow for study analyte measurement. Controls were matched 1:1 to case patients by age (per 10 year strata), gender and diabetes status as these variables are associated with cystatin C or BTP independently of GFR $[18,25]$.

Cystatin C (cysC), BTP (Siemen's nephelometric assays) and $\mathrm{Cr}$ (Vitros Chemistry enzymatic assay) were measured at the Children's Hospital of Eastern Ontario, ON, Canada. The BTP/cysC ratio was calculated for each subject. The $\mathrm{BTP} / \mathrm{cys} \mathrm{C}$ ratio was chosen in lieu of the $\mathrm{BTP} / \mathrm{Cr}$ ratio due to the well-recognized inaccuracy of serum creatinine as a marker of GFR in the setting of hepatic dysfunction. Prior studies have shown a strong inverse relationship between inulin GFR and cysC in cirrhotic patients and a lack of impact of cirrhosis on serum cysC levels, suggesting that cysC is an acceptable surrogate for measured GFR $[20,26]$. As the control group had known CKD, the $\mathrm{BTP} /$ cysC ratio was selected for the outcome instead of the BTP serum concentration in order to adjust for GFR. The difference in mean $\mathrm{BTP} / \mathrm{cys} \mathrm{C}$ ratio between the groups was compared using t-tests. This was repeated after subdividing patients by Child Pugh classification. Similar analysis was done using BTP/Cr. The BTP/cysC and BTP/Cr ratios of the combined Child Pugh B and C category cirrhotics were compared using $t$ tests to those of the Child Pugh A category cirrhotic case subjects.

\section{Results}

A total of 99 case patients were recruited over the study period and were matched with 99 controls. Patient characteristics are shown in Table 2. As expected, case and control subjects were similar with respect to age, gender and diabetic status. Thirty one percent of both case and control groups were diabetic. The most common etiology of cirrhosis was hepatitis C (38\%). The majority of case patients had compensated cirrhosis (61\% Child Pugh A). Mean MELD score was $11.0 \pm 3.8$. Mean $\mathrm{Cr}$ was significantly higher in controls (2.59 vs 0.85 in cirrhotics, $p<0.001)$. BTP and cysC were also higher in 
Table 2 Case and control subject characteristics

\begin{tabular}{lllc}
\hline Characteristic & Case $(n=99)$ & Controls $(n=99)$ & $P$ value \\
\hline Male, N (\%) & $70(71)$ & $70(71)$ & 0.88 \\
Age, (SD) years & $59.4(7.9)$ & $60.4(8.6)$ & 0.40 \\
Diabetes, N(\%) & $31(31)$ & $31(31)$ & 0.88 \\
Cirrhosis etiology & & Not applicable
\end{tabular}

Hepatitis C 38 (38)

Ethanol $21(21)$

NASH $21(21)$

$\begin{array}{ll}\text { Hepatitis B } & 2(2) \\ \text { Autoimmune } & 2(2) \\ \text { Other (PBC, NYD) } & 6(6)\end{array}$

$\mathrm{Cr}$, mean (SD), $95 \% \mathrm{Cl}, \mathrm{mg} / \mathrm{dL}$

$\begin{array}{lllll} & 0.77-0.93 & 2.50-2.67 & \\ \text { BTP, mean (SD), 95\% Cl, mg/L } & 0.93(0.41) & 1.92(1.4) & <0.001 \\ & 0.85-1.01 & 1.84-2.00 & \\ \text { CysC, mean (SD), 95\% Cl, mg/L } & 1.17(0.44) & 2.24(1.16) & <0.001 \\ & 1.09-1.25 & 2.16-2.32 & \\ \text { Bilirubin } & & \text { Not measured } & \end{array}$

$\begin{array}{ll}\text { mean (SD), mg/dL } & 1.6(1.4) \\ <2 \mathrm{mg} / \mathrm{dL}, \mathrm{N}(\%) & 77(78) \\ 2-3 \mathrm{mg} / \mathrm{dL}, \mathrm{N}(\%) & 9(9) \\ >3 \mathrm{mg} / \mathrm{dL}, \mathrm{N}(\%) & 13(13)\end{array}$

Albumin

$\begin{array}{ll}\text { mean (SD), g/dL } & 3.4(0.6) \\ >3.5 \mathrm{~g} / \mathrm{dL}, \mathrm{N}(\%) & 47(48) \\ 2.8-3.5 \mathrm{~g} / \mathrm{dL}, \mathrm{N}(\%) & 42(42) \\ <2.8 \mathrm{~g} / \mathrm{dL}, \mathrm{N}(\%) & 10(10)\end{array}$

$$
\text { INR }
$$

$\begin{array}{cl}\text { mean (SD) } & 1.3(0.3) \\ <1.7, \mathrm{~N}(\%) & 90(91) \\ 1.7-2.3, \mathrm{~N}(\%) & 8(8) \\ >2.3, \mathrm{~N}(\%) & 1(1) \\ \text { Ascites } \mathrm{N}(\%) & \end{array}$

Ascites N(\%)

$\begin{array}{lll}\text { None, } & 64(65) & 99 \\ \text { Mild, } & 33(33) & 0 \\ \text { Moderate-Severe } & 2(2) & 0 \\ \text { Encephalopathy, N(\%) } & & \\ \text { None } & 80(81) & 99 \\ \text { Grade I-II } & 19(19) & 0 \\ \text { Grade III-IV } & 0(0) & 0\end{array}$

CHILD PUGH category N (\%)

$\begin{array}{lll}\text { A } & 60(61) \quad \text { Not applicable } \\ \text { B } & 27(27) \\ \text { C } & 12(12)\end{array}$

Table 2 Case and control subject characteristics (Continued)

\begin{tabular}{|c|c|c|c|}
\hline Characteristic & Case $(n=99)$ & Controls $(n=99)$ & $P$ value \\
\hline \multicolumn{4}{|c|}{ MELD score N (\%) } \\
\hline$\leq 9.4$ & $50(47.6)$ & Not applicable & \\
\hline $9.5-19$ & $51(48.6)$ & & \\
\hline $20-29$ & $4(3.8)$ & & \\
\hline
\end{tabular}

the control groups. Scatterplots of the analyte concentrations (case vs controls and Child Pugh A vs Child Pugh $\mathrm{B} \& \mathrm{C})$ are found in Fig. 1.

Figure 2 shows the ratios between the analytes. There were no significant differences between the control and case BTP/cysC ratios for the whole cohort or for any of the Child Pugh Classes. In comparison, there was a significantly higher $\mathrm{BTP} / \mathrm{Cr}$ ratio in the case group as compared to the control group for the entire cohort and for each of the Child Pugh Classes.

The BTP/Cr ratio was higher for the combined Child Pugh $\mathrm{B} \& \mathrm{C}$ as compared to the Child Pugh A case subjects $(1.20$ vs $1.03, p<0.01)$. There was no difference in the BTP/cysC ratios between the combined Child Pugh $\mathrm{B} \& \mathrm{C}$ and Child Pugh A cirrhotic groups $(p=0.25)$.

\section{Discussion}

In this study, we have shown that the serum BTP concentration is not affected by the presence of cirrhosis. $\mathrm{BTP} / \mathrm{cys} \mathrm{C}$ ratios were similar to controls, even in those with the most advanced hepatic dysfunction. The lack of $\mathrm{BTP} /$ cysC ratio differences between the different Child Pugh categories further supports the absence of hepatic effect on BTP. This is in contrast to what is observed with serum $\mathrm{Cr}$. The higher BTP/Cr ratios in the cirrhotic group and in cirrhotics with more advanced disease reflect a well-recognized decrease in $\mathrm{Cr}$ production in the setting of cirrhosis [20].

BTP for GFR prediction in the setting of cirrhosis was recently investigated by Mindikoglu et al. [22] GFR was measured by plasma clearance of iothalamate and serum was sampled for Cr, cysC, BTP and other analytes in 103 patients with cirrhosis. Regression analysis was used to develop a novel GFR prediction equation. The authors found that adding BTP to cycC and $\mathrm{Cr}$ did not confer any additional benefit for GFR prediction [22]. This study is somewhat hampered by the use of plasma clearance technique for GFR determination in most subjects. Plasma clearance protocols have been shown to be inaccurate in cirrhosis due to tracer sequestration into inaccessible compartments (ascites, peripheral edema) and are therefore not recommended for GFR assessment in this special population [27, 28]. Nonetheless, the study findings are consistent with what has been reported in other noncirrhotic populations [16]. 
a

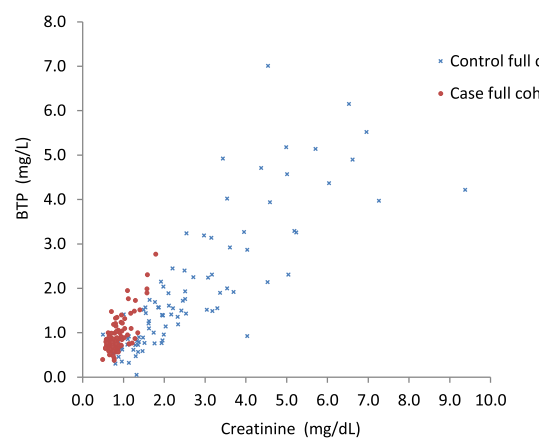

C

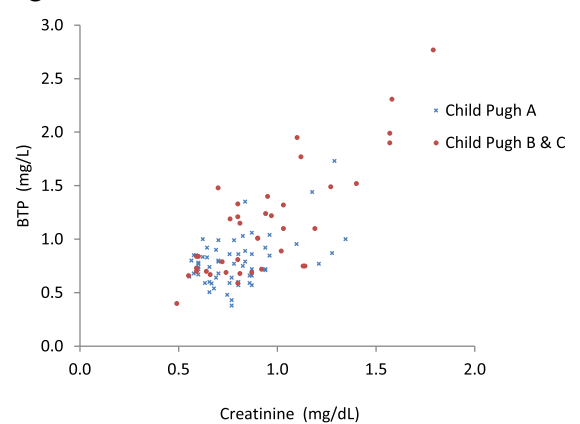

b

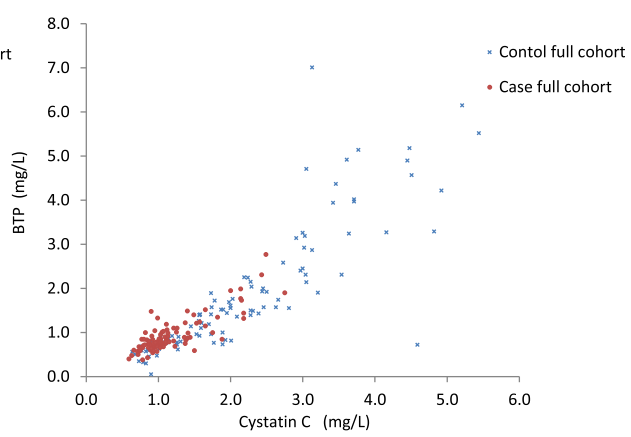

d

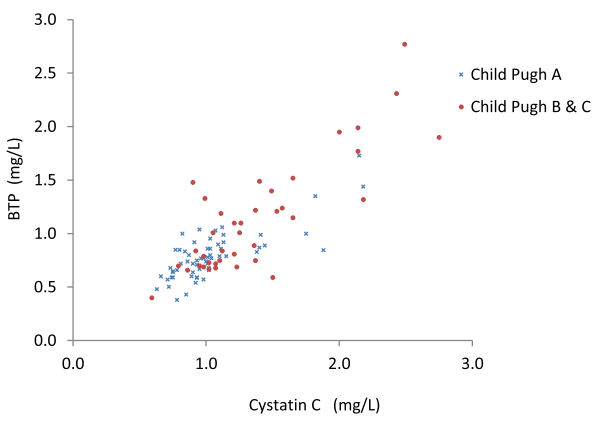

Fig. 1 Scatterplots of analytes concentrations: (a) BTP (mg/L) and Creatinine (mg/dL) in full cohort cases and controls: (b) BTP (mg/L) and CysC (mg/dL) in full cohort cases and controls: (c) BTP (mg/L) and Creatinine (mg/dL) in Child Puch A and Child Pugh B\&C; (d) BTP (mg/L) and Cystatin C (mg/L) in Child Puch A and Child Pugh B\&C

Our novel results argue against a significant role for the liver in the metabolism of BTP. Other hypothesis must therefore be explored to explain the relative amounts of different BTP isoforms that has been observed in different fluid compartments. An alternate potential explanation for our findings is that the anti-BTP antibodies used in Siemens's nephelometric assay might not recognize epitopes present in the "brain type" isoforms. The Siemens assay uses polyclonal antibodies directed against human urinary BTP and therefore could theoretically not bind to brain type BTP isoforms. In this case, elevated brain BTP isoforms may exist but are simply not detectable.

Limitations include the use of CKD patients as the control group. This patient group was selected as control for pragmatic reasons: their co-morbidities are well documented, they are numerous and, unlike most other patient groups, they have routine phlebotomy with large volumes of residual plasma in which additional analytes can be measured. The absence of measured GFR is another limitation. Measuring GFR using
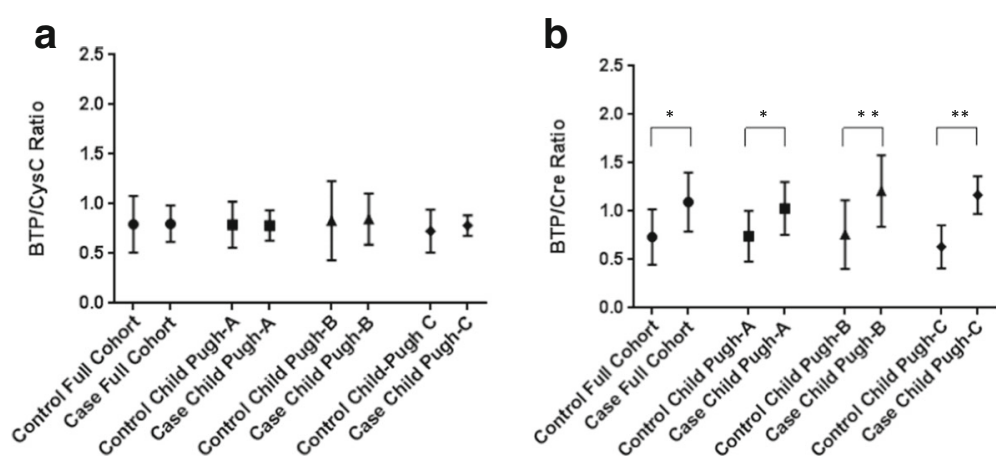

Fig. 2 Mean BTP/CysC (a) and BTP/Cr ratios (b). Data are presented as the mean and standard deviation. There are no significant differences in BTP/cysC ratios between case and control groups $(p>0.10)$. The BTP/Cr ratios are significantly higher in the case groups as compared to the control groups for all three Child Pugh Categories. ${ }^{*} p<0.001$, ${ }^{* *} p<0.01$ 
exogenous markers is expensive and cumbersome particularly in the setting of cirrhosis which requires the more difficult urinary clearance methods to prevent GFR overestimation due to tracer clearance in extravascular compartments. Confirmation of study findings using a measured GFR would be beneficial. Finally, only $12 \%$ of the study population have advanced cirrhosis (12\% Child Pugh C) which hinders extrapolation of study findings to those with advanced disease.

\section{Conclusions}

It is well recognized that a number of factors (muscle mass, diet, hepatic function) influence serum $\mathrm{Cr}$ independently of GFR and these contribute significantly to the difficulties in accurately assessing GFR using $\mathrm{Cr}[22,29]$. This study suggests that, unlike serum Cr, serum BTP concentrations are independent of hepatic dysfunction. Additional studies exploring any incremental benefit of adding BTP to the existing panel of endogenous GFR markers in cirrhosis are needed. In addition, further study of other non-GFR dependent factors which may influence serum BTP concentration levels is required to allow for a better understanding of how to best incorporate BTP into clinical care.

\section{Abbreviations}

BTP: Beta trace protein; CKD: Chronic kidney disease; Cr: Creatinine; CysC: Cystatin C; GFR: Glomerular filtration rate; MELD: Model for end-stage liver disease

\section{Funding}

Department of Medicine, Innovation Fund, Queen's University, Kingston, ON, Canada. The funding source had no role in design of study, collection, analysis or interpretation of data or in manuscript writing.

\section{Authors' contributions}

All authors contributed to the study. CW, GK and AA were involved in study conception and design, data analysis and manuscript preparation. DC, JF and $\mathrm{CL}$ assisted with study design, study execution and manuscript preparation. TA helped in data analysis and manuscript preparation. All have reviewed and approved the final manuscript.

\section{Author's information}

CW has been actively involved in original research on BTP for 10 years, has investigated different aspects of BTP as a marker of GFR with several related published research articles in the field. Most recently, she published a comprehensive review of BTP (American Journal of Kidney Diseases 2015;65(1):131-46) in which she discussed the role of hepatic fucntion in BTP metabolism and its potential impact on serum concentrations.

\section{Ethics approval and consent to participate}

Ethics approval was obtained from the Queen's University Health Sciences Research Ethics Board. Cirrhotic patients provided written consent for study participation.

\section{Consent for publication}

Not applicable.

\section{Competing interests}

The authors declare that they have no competing interests to declare.

\section{Publisher's Note}

Springer Nature remains neutral with regard to jurisdictional claims in published maps and institutional affiliations.

\section{Author details}

'Division of Nephrology, Department of Medicine, Queen's University, Etherington Hall, 94 Stuart Street, Kingston, ON K7L 2N6, Canada. ${ }^{2}$ Division of Nephrology, Department of Medicine, University of Ottawa, Ottawa, ON, Canada. ${ }^{3}$ Kidney Research Centre, Ottawa Health Research Institute, Ottawa, ON, Canada. ${ }^{4}$ Clinical Epidemiology Program, Ottawa Health Research Institute, Ottawa, ON, Canada. ${ }^{5}$ Division of Gastroenterology, Department of Medicine, Queen's University, Kingston, ON, Canada. ${ }^{6}$ Department of Public Health Sciences, Queen's University, Kingston, ON, Canada.

Received: 17 February 2016 Accepted: 21 March 2018 Published online: 13 April 2018

\section{References}

1. White CA, Ghazan-Shahi S, Adams MA. Beta trace protein: a complex marker of GFR and tissue injury. Am J Kidney Dis. 2015;65(1):131-46.

2. Clausen J. Proteins in normal cerebrospinal fluid not found in serum. Proc Soc Exp Biol Med. 1961;109:91-5.

3. Hoffmann A, Nimtz M, Conradt HS. Molecular characterization of beta-trace protein in human serum and urine: a potential diagnostic marker for renal diseases. Glycobiology. 1997;7:499-506.

4. Filler G, Priem F, Lepage N, Sinha P, Vollmer I, Clark H, Keely E, Matzinger M, Akbari A, Althaus H, Jung K. Beta-trace protein, cystatin C, beta(2)microglobulin, and creatinine compared for detecting impaired glomerular filtration rates in children. Clin Chem. 2002;48:729-36.

5. Giessing M. Beta-trace protein as indicator of glomerular filtration rate. Urology. 1999;54:940-1.

6. Priem F, Althaus H, Birnbaum M, Sinha P, Conradt HS, Jung K. Beta-trace protein in serum: a new marker of glomerular filtration rate in the creatinine-blind range. Clin Chem. 1999;45:567-8.

7. Spanaus KS, Kollerits B, Ritz E, Hersberger M, Kronenberg F, von Eckardstein A. Serum creatinine, cystatin $C$, and beta-trace protein in diagnostic staging and predicting progression of primary nondiabetic chronic kidney disease. Clin Chem. 2010;56:740-9.

8. Inker LA, Tighiouart $\mathrm{H}$, Coresh J, et al. GFR estimation using Beta-trace protein and B2-microglobulin in CKD. Am J Kidney Dis. 2016;67:40-8.

9. White CA, Akbari A, Doucette $S$, et al. Estimating GFR using serum beta trace protein: accuracy and validation in kidney transplant and pediatric populations. Kidney Int. 2009;76:784-91.

10. Poge U, Gerhardt TM, Stoffel-Wagner B, et al. Beta-trace protein is an alternative marker for glomerular filtration rate in renal transplantation patients.[see comment]. Clin Chem. 2005;51(8):1531-3.

11. Kobata M, Shimizu A, Rinno H, et al. Beta-trace protein, a new marker of GFR, may predict the early prognostic stages of patients with type 2 diabetic nephropathy. J Clin Lab Anal. 2004;18(4):237-9.

12. White CA, Akbari A, Doucette $S$, et al. A novel equation to estimate glomerular filtration rate using Beta-trace protein. Clin Chem. 2007; 53(11):1965-8.

13. Poge U, Gerhardt T, Stoffel-Wagner B, Palmedo H, Klehr HU, Sauerbruch T, Woitas RP. Beta-trace protein-based equations for calculation of GFR in renal transplant recipients. Am J Transplant. 2008;8:608-15.

14. Abbink FC, Laarman CA, Braam Kl, van Wijk JA, Kors WA, Bouman AA, Spreeuwenberg MD, Stoffel-Wagner B, Bokenkamp A. Beta-trace protein is not superior to cystatin $C$ for the estimation of GFR in patients receiving corticosteroids. Clin Biochem. 2008:41:299-305.

15. Benlamri A, Nadarajah R, Yasin A, Lepage N, Sharma AP, Filler G. Development of a beta-trace protein based formula for estimation of glomerular filtration rate. Pediatr Nephrol. 2010;25:485-90.

16 Werner K, Pihlsgard M, Elmstahl S, Legrand H, Nyman U, Christensson A Combining cystatin $C$ and creatinine yields a reliable glomerular filtration rate estimation in older adults in contrast to beta-trace protein and beta2microglobulin. Nephron. 2017;137:29-37.

17 Liu X, Foster MC, Tighiouart H, Anderson AH, Beck GJ, Contreras G, Coresh J, Eckfeldt JH, Feldman HI, Greene T, Hamm LL, He J, Horwitz E, Lewis J, Ricardo AC, Shou H, Townsend RR, Weir MR, Inker LA, Levey AS. Non-GFR determinants of low-molecular-weight serum protein filtration markers in CKD. Am J Kidney Dis. 2016;68:892-900.

18 White CA, Akbari A, Doucette S, Fergusson D, Ramsay T, Hussain N, Dinh L, Filler G, Lepage N, Knoll GA. Effect of clinical variables and immunosuppression on serum cystatin $C$ and beta-trace protein in kidney transplant recipients. Am J Kidney Dis. 2009;54:922-30. 
19 Li W, Mase M, Inui T, Shimoda M, Isomura K, Oda H, Yamada K, Urade Y. Pharmacokinetics of recombinant human lipocalin-type prostaglandin D synthase/beta-trace in canine. Neurosci Res. 2008;61:289-93.

20 Orlando R, Mussap M, Plebani M, Piccoli P, De MS, Floreani M, Padrini R, Palatini P. Diagnostic value of plasma cystatin $C$ as a glomerular filtration marker in decompensated liver cirrhosis. Clin Chem. 2002;48:t-8.

21 Caregaro L, Menon F, Angeli P, Amodio P, Merkel C, Bortoluzzi A, Alberino F, Gatta A. Limitations of serum creatinine level and creatinine clearance as filtration markers in cirrhosis. Arch Intern Med. 1994;154:201-5.

22 Mindikoglu AL, Dowling TC, Magder LS, et al. Estimation of glomerular filtration rate in patients with cirrhosis by using new and conventional filtration markers and Dimethylarginines. Clin Gastroenterol Hepatol. 2016;14:624-32.

23 Wiesner RH, McDiarmid SV, Kamath PS, Edwards EB, Malinchoc M, Kremers WK, Krom RA, Kim WR. MELD and PELD: application of survival models to liver allocation. Liver Transpl. 2001;7:567.

24 Pugh RN, Murray-Lyon IM, Dawson JL, Pietroni MC, Williams R. Transection of the oesophagus for bleeding oesophageal varices. Brit J Surg. 1973:60:646-9.

25 Stevens LA, Schmid CH, Greene T, Li L, Beck GJ, Joffe MM, Froissart M, Kusek JW, Zhang YL, Coresh J, Levey AS. Factors other than glomerular filtration rate affect serum cystatin C levels. Kidney Int. 2009;75:652-60.

26 Woitas RP, Stoffel-Wagner B, Flommersfeld S, Poege U, Schiedermaier P, Klehr HU, Spengler U, Bidlingmaier F, Sauerbruch T. Correlation of serum concentrations of cystatin $C$ and creatinine to inulin clearance in liver cirrhosis. Clin Chem. 2000:46:712-5.

27 Skluzacek PA, Szewc RG, Nolan CR III, Riley DJ, Lee S, Pergola PE. Prediction of GFR in liver transplant candidates. Am J Kidney Dis. 2003:42(6):1169-76.

28 Henriksen JH, Brochner-Mortensen J, Malchow-Moller A, Schlichting P. Overestimation of glomerular filtration rate by single injection [51Cr]EDTA plasma clearance determination in patients with ascites. Scan J Clin Lab Inv. 1980;40:279-84

29 Levey AS. Measurement of renal function in chronic renal disease. Kidney Int. 1990;38:167-84.

\section{Submit your next manuscript to BioMed Central and we will help you at every step:}

- We accept pre-submission inquiries

- Our selector tool helps you to find the most relevant journal

- We provide round the clock customer support

- Convenient online submission

- Thorough peer review

- Inclusion in PubMed and all major indexing services

- Maximum visibility for your research

Submit your manuscript at www.biomedcentral.com/submit 